Research Articles

\title{
Occurrence of Feline Immunodeficiency Virus (FIV) and Feline Leukemia (FeLV) in São Luís-MA
}

\author{
${ }^{1}$ Nathálya dos Santos Martins, ${ }^{2}$ Ana Paula Sousa Rodrigues, \\ ${ }^{2}$ Stefanne Aparecida Gonçalves, ${ }^{1}$ Ana Lucia Abreu Silva, ${ }^{3}$ Rudson Almeida de Oliveira, \\ ${ }^{2}$ Jenner Karlisson Pimenta dos Reis and ${ }^{1}$ Ferdinan Almeida Melo
}

${ }^{I}$ Departamento de Patologia Veterinária, Universidade Estadual do Maranhão, Cidade Universitária Paulo VI, Cx. Postal 9, Tirical, São Luís, MA 65055-970, Brazil

${ }^{2}$ Departamento de Medicina Veterinária Preventiva, Escola de Veterinária,

Universidade Federal de Minas Gerais, UFMG-30 123-970, Belo Horizonte, MG, Brazil

${ }^{3}$ Departamento das Clínicas Veterinárias, Universidade Estadual do Maranhão,

Cidade Universitária Paulo VI, Cx. Postal 9, Tirical, São Luís, MA 65055-970, Brazil

Article history

Received: 29-01-2015

Revised: 12-6-2015

Accepted: 2-7-2015

Corresponding Auhtor: Nathálya dos Santos Martins Departamento de Patologia Veterinária, Universidade Estadual do Maranhão, Cidade Universitária Paulo VI, Cx.

Postal 9, Tirical, São Luís, MA 65055-970, Brazil

Email: martinsns.nathalya@gmail.com

\begin{abstract}
The aim of this study was to evaluate the occurrence of feline immunodeficiency virus and feline leukemia virus in the city of São Luís, Maranhão state (MA), Brazil. A total of 120 blood samples were tested using the Polymerase Chain Reaction (PCR) to detect the proviral DNA, with an amplification of a fragment of 244bp of the FIV's gene gag. To detect antiFIV antibodies and the p27antigen of FeLV, the samples were tested with a commercial immunoassay kit, SNAP Combo Plus (IDEXX ${ }^{\circledR}$ Laboratories, USA), an indirect ELISA was also carried out for FIV. All three tests used gave $18.33 \%(22 / 120)$ of positivity for FIV. PCR and indirect ELISA found $10.83 \%(13 / 120)$ of the animals with FIV, while the SNAP Combo Plus found $9.17 \%(11 / 120)$. Only $0.83 \%(1 / 120)$ of the samples were positive for FeLV in the SNAP combo plus. Comparatively, SNAP combo plus showed higher sensitivity, whereas the indirect ELISA and PCR had, similar and better specificity $(\mathrm{p}<0.05)$. The small difference between the tests (all above $90 \%$ ) indicates that they are highly specific and have a high VPN, implying that they have the capacity to distinguish true negatives. Therefore, this study concluded that FIV is present in São Luís and that the clinical disease exists in Maranhão state, whereas for FeLV, there was only one seropositive animal which did not show any symptoms.
\end{abstract}

Keywords: Feline Immunodeficiency Virus (FIV), Feline Leukemia (FeLV), Polymerase Chain Reaction, ELISA, São Luís

\section{Introduction}

The Feline Immunodeficiency Virus (FIV) is a lentivirus of the Retroviridae family; it results in chronic inflammatory conditions, neoplastics diseases and secondary infections in felines. Some of the characteristics of FIV, such as structural, morphological, biochemical and genetic, are similar to the Human Immunodeficiency Virus (HIV) and can thus be a useful animal model for the study of HIV (Hartmann et al., 2011).

The virus infects preferentially mononuclear cells of the peripheral blood and shows tropism for lymphocytes T CD4+ (Paillot et al., 2005). Infected cats produce specific neutralizing antibodies against the viral proteins p15 and p24 between 2 and 4 weeks after the infection (English et al., 1993). Titers of specific antibodies rise, gradually, in few weeks, as a result of the viral infection (Yamamoto et al., 1998).

Clinically, the Feline Acquired Immune Deficiency Syndrome (FAIDS) can be characterized by four stages: Acute, that can last from months until years, where the infected animal can show neutropenia, fever, lethargy, lymphadenopathy, weight loss; asymptomatic, that can last years, where the animal has no clinical symptoms, but can show a progressive decline in CD4+ cells number; AIDS Related Complex (ARC) can take months for the infected cat show symptoms such as: Generalized lymphadenopathy, recurrent fever, apathy, leucopenia, anemia, anorexia, 
depression, chronic rhinitis, glomerulonephritis, weight loss, chronic gingivitis and stomatitis and behavioral changes; FAIDS that takes months and the animal shows the symptoms presents in ARC and immunodeficiency, opportunist infections, neoplasias and neurological abnormalities (Hartmann et al., 2011).

The prevalence of the disease in different feline populations around the world has been shown to vary from 2.5 to $44 \%$ in epidemiological studies (Lara et al., 2008). However, using molecular methods, this prevalence decreases to 4 to $2 \%$ of the worldwide cat population (Hayward et al., 2007). This variation is due to population density, reproductive status, age, gender and living conditions, in particular the frequency of street visitation and reproductive disputes (Norris et al., 2007). In Brazil, FIV has been detected through serological research and $\mathrm{PCR}$, in domiciled and straydomestic cats, in São Paulo, Rio de Janeiro, Rio Grande do Sul and Minas Geraisstates, with a prevalence that varied between 2 and $37.5 \%$ for FIV and 8 to $63 \%$ for FeLV (Caldas et al., 2000; Souza et al., 2002; Caxito et al., 2006; Almeida et al., 2004).

Nowadays, the methods used to detect FIV infection in cats include virus isolation, direct and indirect immunological tests and molecular tests. Specificity and sensitivity of the serological tests are quite satisfactory, but there are reports of false-positives and false-negatives (Hosie and Jarrett, 1990). Isolation of FIV in mononuclear cell cultures of peripheral blood from negative serological cats have beendescribed (Sparkes et al., 1993), however this is not a routine laboratory method. Seroconversion can occur after a period of 14 months post infection (Yamamoto et al., 1998).

Diagnose is, on most cases, done by specific antibodies anti-FIV detection, once most cases the antigenic level remains below the threshold detection (Richards et al., 2006).

Polymerase Chain Reaction (PCR) allows provirus detection, however its specificity and sensibility has been described as highly variable, from 40 to $100 \%$ (Lairmore, 2011). It is particularly useful in cases where the animal has the provirus, but doesn't produce antiFIV antibodies (Sellon and Hartmann, 2006).

The Feline Leukemia Virus (FeLV), belongs to the Retroviridaefamily and Gammaretrovirusgenus, it can infect domestic cats and wild felines sporadically. This feline retrovirus is associated to a series of degenerative or proliferative diseases, such as leukemias and lymphomas. Leukemia and lymphoma are common manifestations of the infection caused by FeLV in persistently infected animals, however the development of anemias, neurological diseases and immunodeficienciesaremore frequent (Levy et al., 2008; Torres et al., 2010).
Manifestations associated to FeLV virus are divided into proliferative or degenerative diseases. Hematological disorders, particularly cytopenias due to myelosuppression suspect, are common findings in infected felines, non-neoplastic hematological disorders include, myelodysplastic syndrome, aplastic anemia (pancytopenia); cyclic, persistent or transitory neutropenias; panleucopenic syndrome and platelets abnormalities. Around $10 \%$ of the FeLV associated anemias are regenerative and caused by immunomediated hemolysis or secondary to hemoplasma infections and the rest of FeLV related anemias $(90 \%)$ are non-regenerative and caused by myelosuppression (Stutzer et al., 2010).

This retrovirus infection can be diagnosed by the p27 viral antigen detection in leucocytes, plasma, serum, tears or saliva from infected animals. The tests most used are Antibody Immune Fluorescence (AIF) and direct immunoassay (Torres et al., 2010). However, molecular tests, such as polymerase chain reaction, are being frequently used due to its advantages on serological tests, because it detects and identify the viral agents and also allows them to be genetically characterized (Tandon et al., 2008).

Therefore, the aim of this study was to evaluate the occurrence of FIV and FeLV in São Luís-MA, comparing the techniques of PCR (Hohdatsu et al., 1992), indirect Elisa (Alves et al., 2011) and SNAP Combo Plus (ELISA-SNAP ${ }^{\circledR}$ Combo FeLV/FIV) for FIV diagnoses.

\section{Materials and Methods}

A set of 120 blood samples from domestic cats (Feliscatusdomesticus) were used, independent of gender, breed, age and life style, with or without symptoms of any disease. The samples were randomly collected from visits to the Francisco EdilbertoUchôa Lopes University Animal Hospital of Maranhão State University, private veterinary clinics, animalsfrom the UEMA campus and animal shelters in São Luís - MA. The present study was submitted and approved, to the Ethics Committee and Animal Testing (CEEA) of the Veterinary College of Maranhão State University UEMA, under the protocol 041/2012.

The serum samples were submitted to immunochromatography, using the commercial kit SNAP Combo Plus (IDEXX ${ }^{\circledR}$ Laboratories, USA) to verify the presence of antibodies against the FIV protein p24 and the FeLV protein p27. The indirect ELISA used was the one standardized by Alves et al. (2011), using $2.5 \mathrm{ng} / \mathrm{mL}$ of the FIV recombinant protein p24 (r-p24) adsorbed onto the plate, 1:320 diluted serum and conjugated (peroxidase anti-cat IgG/SIGMAALDRICH) at 1:7500 dilution. 
To perform the molecular tests, total DNA extraction of peripheral monunuclears cells was carried out, using the QIAamp DNA Mini Kit (QIAGEN), carefully following the manufacturer's recommendations in order to obtain the same amount of DNA from all samples. The samples were thenquantified with a NanoVuePlus Spectrophotometer (GE Healthcare, Piscataway, NJ, USA) using a $2 \mu \mathrm{L}$ aliquot and later stored at $-20^{\circ} \mathrm{C}$ until PCR performance. For FIV detection,oligonucleotides primers were used as sense 5'CTAGGAGGTGAGGAAGTTCA-3' and anti-sense 5' CTGCTTGTTGTTCTTGAGTT-3' that amplify the target fragment of $244 \mathrm{pb}$ inside the coding region of the FIV gag gene as described by Hohdatsu et al. (1992). With the exception of the DNA, all reagents were combined together in a mix containing: $5 \mathrm{U}$ of Taq DNA polymerase (Invitrogen Life Technologies ${ }^{\circledR}$, Brazil); 5.1 $\mu \mathrm{L}$ of buffered PCR $5 \mathrm{X}, 25 \mathrm{mM}$ of $\mathrm{Mgcl} 2,10 \mathrm{mM}$ of dNTP (deoxyribonucleotide 5'-triphosphate-dATP, dCTP, dGTP and Dttp-GE Healthcare), 5 pmol of each oligonucleotide (Invitrogen Life Technologies ${ }^{\circledR}$, Brazil) and $11.84 \mu \mathrm{L}$ of ultrapure water (Sigma). After the mix, $2 \mu \mathrm{L}$ of DNA from each sample was added, reaching a final volume of $25 \mu \mathrm{L}$. A negative control was added to each amplification essayperformed by adding ultrapure water instead of the DNA.

Amplification cycles were performed in a thermal cycler Applied Biosystems (ABI), 96-well Veriti model Thermal Cycler, with initial denaturation at $94^{\circ} \mathrm{C}$ for 5 min, followed by 35 cycles, each one consisting of denaturation at $94^{\circ} \mathrm{C}$ for 1 minute, annealing at $55^{\circ} \mathrm{C}$ for $2 \mathrm{~min}$, polymerase extension at $72^{\circ} \mathrm{C}$ for $2 \mathrm{~min}$ and a final extension at $72^{\circ} \mathrm{C}$ for $5 \mathrm{~min}$. After the cycles, the amplified products were visualized in agar gel at $1.5 \%$ TAE buffered, stained with ethidium bromide in an ultraviolet transilluminator and photo documented.

The Fisher's Exact Test was used to compareamongthe SNAP Combo plus, PCR and indirect ELISA techniques for the diagnosis of FIV, as well as sensitivity and specificity calculations. To evaluate the concordance index between the tests, the Kappa $(\kappa)$ test was carried out, as well as verifying the predictive positive and negative values. Univariate analysis was performed considering the characteristics of the animal (breed, sex and age) and the epidemiological characteristics (origin, living place, contactants, outside access and reproductive life) using the Fisher's Exact Test and the calculating risk rate (OR). The analyses were performed using the statistical package GraphPadInstat version 3.05. All statistical analyses were performed according a minimal significance level of $5 \%(\mathrm{p}<0.05)$.

\section{Results}

A total of $18.33 \%(22 / 120)$ of the sample was positive for FIV, considering all the tests used; $10.83 \%$ $(13 / 120)$ via PCR, $9.17 \%(11 / 120)$ via SNAP combo plus and $10.83 \%(13 / 120)$ via indirect ELISA and the Chi-Square Test $\left(\chi^{2}\right)$ verified that there was no significant association ( $p>0.05)$ between the test used for diagnosis and positivity for FIV (Table 1). However, for FeLV, of the 120 samples analyzed, only $0.83 \%(1 / 120)$ were positive via SNAP combo plus. This FeLV positive animal wasnot positive for FIV in the three tests used.

Noting the distribution of the positive samples for FIV according to the quantity of tests used, it is seen that $54.55 \%(12 / 22)$ were positive in only one test; $27.27 \%(6 / 22)$ in two and $18.18 \%(4 / 22)$ in the three tests, indicating a variation of sensitivity and specificity among them.

Analyzing serological and molecular assays, a divergence of 18 samples was seen in the tests used. The SNAP combo plus test showed the highest sensitivity, achieving $72.73 \%$ and $95.41 \%$ of specificity and a kappa test result of $0.63 \%$. Indirect ELISA showed a specificity of $97.20 \%$ and sensitivity of $61.54 \%$, also with a kappa test result of $0.63 \%$, showing good accordance between them (Table 2).

Within the clinical symptoms seen at the clinical exam of FIV and FeLV positive animals, gingivitis, stomatitis or gingivostomatitis, dermatological, ophthalmic, respiratory and genitourinary alterations, in addition to cachexia, dehydration, lymphadenopathy, diarrhea and fever.

Univariate analysis of association of the animals characteristics (breed, sex and age) and positivity for FIV, revealed significant associations between positive animals and the variables sex $(\mathrm{p}<0.05)$ and age $(\mathrm{p}<0.01)$. These results demonstrate that the possibility of infection is higher for males, $12.5 \%(15 / 120)$, than for females $5.83 \%(07 / 120)$ and according to age, animals more than three years old have $39.29 \%$ (11/28) of being FIV positive compared to $11.96 \%$ (11/92) of being FIV positivewhen less than three years old. Therefore, males more than three years old (ORs $=$ 2.857 and 4.765 , respectively) have a higher probability to be seropositive.

For the variable breed, there was no significant statistic association ( $p>0.05$ ) for FIV positivity, although there was a higher percentage for moggies (without defined breed); however, most of the animals didnot have a specific breed.

The univariate analysis related to epidemiological characteristics (origin, living place, contactants, outside access and reproductive life) and positivity for FIV, showed a highly significant association $(\mathrm{p}<0.01)$ between positive animals and the variable contactants. In these cases animal+s that had at least one contactanthad $9.716(\mathrm{OR})$ times more likelihood to have the infection. 
Table 1. Feline percentage distribution, from São Luís- MA, according to the test used to detect FIV virus and its positivity

\begin{tabular}{lll}
\hline Testsused & Positives $(\%)$ & Negatives $(\%)$ \\
\hline PCR & $10,83^{\mathrm{a}}(13 / 120)$ & $89,17(107 / 120)$ \\
Indirect ELISA & $10,83^{\mathrm{a}}(13 / 120)$ & $89,17(107 / 120)$ \\
SNAP Combo Plus & $9,17^{\mathrm{a}}(11 / 120)$ & $90,83(109 / 120)$ \\
Total & $18,33(22 / 120)$ & $81,67(98 / 120)$ \\
\hline
\end{tabular}

a-equal letters in the column indicates that there's no significant association ( $\mathrm{p}>0.05)$ between the tests used and FIV positivity. Chi squaretest $\left(\chi^{2}\right)$ for independentsamples. $\chi^{2}=0.8865 ; p=0.2410$

Table 2. Comparative analysis between the tests used to detect FIV in feline samples, from São Luís - MA

\begin{tabular}{|c|c|c|c|c|c|c|c|c|c|c|c|}
\hline & & \multicolumn{10}{|c|}{ SNAP COMBO PLUS } \\
\hline & & POSITIVO & NEGATIVO & TOTAL & SENS $\%$ & $\mathrm{ESP} \%$ & KAPPA & VPP\% & VPN\% & RV & $\mathrm{p}$ \\
\hline \multirow{3}{*}{ PCR } & POSITIVE & $6(5 \%)$ & $7(6 \%)$ & $13(11 \%)$ & \multirow{3}{*}{54.55} & \multirow{3}{*}{93.58} & \multirow{3}{*}{0.45} & \multirow{3}{*}{46.15} & \multirow{3}{*}{95.33} & \multirow{3}{*}{8.494} & \multirow{3}{*}{0.0002} \\
\hline & NEGATIVE & $5(4 \%)$ & $102(85 \%)$ & $107(89 \%)$ & & & & & & & \\
\hline & TOTAL & $11(9 \%)$ & $109(91 \%)$ & $120(100 \%)$ & & & & & & & \\
\hline \multirow{3}{*}{$\begin{array}{l}\text { INDIRECT } \\
\text { ELISA }\end{array}$} & POSITIVE & $8(7 \%)$ & $5(4 \%)$ & $13(11 \%)$ & \multirow{3}{*}{72.73} & \multirow{3}{*}{95.41} & \multirow{3}{*}{0.63} & \multirow{3}{*}{61.54} & \multirow{3}{*}{97.20} & \multirow{3}{*}{15.855} & \multirow{3}{*}{0.0001} \\
\hline & NEGATIVE & $3(3 \%)$ & $104(87 \%)$ & $107(89 \%)$ & & & & & & & \\
\hline & TOTAL & $11(9 \%)$ & $109(91 \%)$ & $120(100 \%)$ & & & & & & & \\
\hline & & \multicolumn{10}{|c|}{ PCR } \\
\hline & & POSITIVO & NEGATIVO & TOTAL & SENS $\%$ & ESP $\%$ & KAPPA & $\mathrm{VPP} \%$ & VPN\% $\%$ & RV & $\mathrm{p}$ \\
\hline \multirow{3}{*}{$\begin{array}{l}\text { SNAP } \\
\text { COMBO } \\
\text { PLUS }\end{array}$} & POSITIVE & $6(5 \%)$ & $5(4 \%)$ & $11(9 \%)$ & \multirow{3}{*}{46.15} & \multirow{3}{*}{95.33} & \multirow{3}{*}{0.45} & \multirow{3}{*}{54.55} & \multirow{3}{*}{93.58} & \multirow{3}{*}{9.877} & \multirow{3}{*}{0.0002} \\
\hline & NEGATIVE & $7(6 \%)$ & $102(85 \%)$ & $109(91 \%)$ & & & & & & & \\
\hline & TOTAL & $13(11 \%)$ & $107(89 \%)$ & $120(100 \%)$ & & & & & & & \\
\hline \multirow{3}{*}{$\begin{array}{l}\text { INDIRECT } \\
\text { ELISA }\end{array}$} & POSITIVE & $4(3 \%)$ & $9(8 \%)$ & $13(11 \%)$ & \multirow{3}{*}{30.77} & \multirow{3}{*}{91.59} & \multirow{3}{*}{0.22} & \multirow{3}{*}{30.77} & & & \\
\hline & NEGATIVE & $9(8 \%)$ & $98(82 \%)$ & $107(89 \%)$ & & & & & 91.59 & 3.658 & 0.0346 \\
\hline & TOTAL & $13(11 \%)$ & $107(89 \%)$ & $120(100 \%)$ & & & & & & & \\
\hline & & & & & INDIF & T ELIS & & & & & \\
\hline & & POSITIVO & NEGATIVO & TOTAL & SENS \% & ESP $\%$ & KAPPA & $\mathrm{VPP} \%$ & VPN\% & RV & $\mathrm{p}$ \\
\hline SNAP & POSITIVE & $8(7 \%)$ & $3(3 \%)$ & $11(9 \%)$ & & & & & & & \\
\hline COMBO & NEGATIVE & $5(4 \%)$ & $104(87 \%)$ & $109(91 \%)$ & 61.54 & 97.20 & 0.63 & 72.73 & 95.41 & 21.949 & $=0.0001$ \\
\hline PLUS & TOTAL & $13(11 \%)$ & $107(89 \%)$ & $120(100 \%)$ & & & & & & & \\
\hline & POSITIVE & $4(3 \%)$ & $9(8 \%)$ & $13(11 \%)$ & & & & & & & \\
\hline PCR & NEGATIVE & $9(8 \%)$ & $98(82 \%)$ & $107(89 \%)$ & 30.77 & 91.59 & 0.22 & 30.77 & 91.59 & 3.658 & 0.0346 \\
\hline & TOTAL & $13(11 \%)$ & $107(89 \%)$ & $120(100 \%)$ & & & & & & & \\
\hline
\end{tabular}

\section{Discussion}

The present study showed a higher positivity percentage for the PCR technique when compared to Marçola et al. (2013), that related 2\% (4/200) of positive animals in Distrito Federal (GO) and to the studies done by Caxito et al. (2006), Teixeira et al. (2007) and Alves et al. (2011), in the city of Belo Horizonte (MG) presenting values of $2.7 \%$ (12/450), $4.14 \%(6 / 145)$ and $6.41 \%(5 / 78)$, of positivity, respectively. However, the values found in São Luís (MA) were lower than the ones related by Lara et al. (2008) that reported an occurrence of $14.8 \%$ (67/454) of felines from 13 cities of São Paulo state and by Souza et al. (2002) who verified positivity of $20.2 \%$ in Rio de Janeiro (RJ) and even lower than those found by Caldas et al. (2000) who described $37.5 \%(15 / 40)$ of seropositive animals in the state of Rio Grande do Sul.

Divergent results can be related to the techniques used, origin of the samples, quantity of samples studied, life style of the studied animals and the genetic variability of the studied virus strain.
In Rio de Janeiro, serological essays determined $16.7 \%$ of the FIV infected animals, among sick animals and their contactants, according to Souza et al. (2002) and $21.0 \%$ according to Almeida et al. (2004). In a research done by Reche Jr. et al. (1997), the authors found $11.7 \%$ (47/401) of serological positivity for FIV and $7.98 \%$ (32/401) for FeLV, studying 123 healthy and 278 sick animals.

In Minas Gerais, Teixeira et al. (2007) noted $32.5 \%$ (13/40) of FeLV positivity, very different from the value seen in São Luís (MA), where only $0.83 \%$ $(1 / 120)$ of seropositive reagent animals were obtained, as described previously and also lower than those found by Reche Jr. et al. (1997) at 7.98\% (32/401).

Comparatively, SNAP combo plus showed higher sensitivity, whereas indirect ELISA and PCR had, similar, higher specificity $(\mathrm{p}<0.05)$. The small specificity difference between the tests (all above 90\%) indicates that they are highly specific and have high PNV, inferring that both have the capacity to distinguish true negatives. Among the tests used in this study, SNAP had the best accuracy, as it is a fast test with specificity 
similar to the other tests, better sensitivity and detects true positives $(\mathrm{p}<0.05)$.

The only test used to diagnose FeLV in this experiment was the Snap combo FIF/FeLV that detects the capsid protein p27 and it is the most commonly used in veterinary clinics. However, it is not capable of identifying animals with latent infection, when there is no viral transcription and indicates viremia 28 days post infection. On the other hand, PCR is capable of detecting up to one copy of the provirus, only a week after the infection (Tandon et al., 2008). Maybe some animals hostedthe latent infection in the bone marrow; therefore it was not detected by the methods used.

Analyzing serological and molecular assays, 18 samples showed a divergence between the tests used. Alves (2010) also found similar results, with 17 conflicting results, using three serological tests (SNAP Combo Plus, indirect Elisa, Western blot) and PCR.

Discordant results in serological detection can occur due to the evolution of infection or crossed reactions. Circulating antibodies show up in two to four weeks after infection and are detectable for the entire life of the animal. In the case of an antibody detection test done in this period (2-4 weeks post infection), false negative resultsmay occur. Kittens must be tested preferentially when they are six months old or more, to avoid interference of maternal antibodies (Caney, 2000).

The importance ofthe PCR technique in veterinary medicine is associated to specific situations when it is not possible to detect antibodies induced by the infection. In relation to FIV, seronegative animals have been shown to react positively to proviral DNA detection (Caldas et al., 2000).

Teixeira et al. (2007) studying shelter animals, demonstrated that $77.8 \%$ (7/9) seropositive for FIV showed clinical alterations, characterized by weight loss, keratopathies, dehydration, respiratory alterations, cystitis and stomatitis. The findings in São Luís showed similarities, with $90.9 \%(20 / 22)$ of positive animals with some kind of clinical alteration.

According to Reche Jr. et al. (1997) FIV infection is more frequent in males than females, in a proportion of $4: 1$, whereas this difference between males and females is not seen in the FeLV infection.

\section{Conclusion}

This work, which is the first registered study on cats in São Luís, concludes that Feline Immunodeficiency Virus (FIV) and feline leukemia virus (FeLV) are present in this city, since the animals showed clinical disease. The group of domestic felines with higher risk can be characterized as males, that are 36 months old or more and have had at least one contactant (ORs: 2.857; 4.765 and 9.716 , respectively). The test with the highest sensitivity was the SNAP Combo plus and indirect Elisa showed the best specificity; however in general there was good accordance among the testsused.

\section{Acknowledgement}

To Master's degree in animal science, CNPQ, CAPES and FAPEMA, for the financial support. To the team at the Retroviruses Laboratory-Retrolab-UFMG who helped with running the ELISA and molecular tests. To the University Veterinary Hospital Francisco EdilbertoUchôaLopes for the collaboration in providing clinical visits and sample collection.

\section{Funding Information}

The project was funded by the Foundation for Research and Technological Development of the State of Maranhão (FAPEMA), with the Universal Notice number 001/2013.

\section{Author's Contributions}

Teachers present in the article contributed directing the research, providing laboratory for the development of the project and graduate students performed all the research proposal.

\section{Ethics}

The present study was submitted and approved, to the Ethics Committee and Animal Testing (CEEA) of the Veterinary College of Maranhão State UniversityUEMA, under the protocol 041/2012.

\section{References}

Alves, F., D.D.S. Rajao, H.L.D. Puerto, G.F. Braz and R.C. Leite et al., 2011. Occurrence of feline immunodeficiency virus and feline leukemia virus infection in cats. Am. J. Anim. Vet., 6: 125-129. DOI: 10.3844/ajavsp.2011.125.129

Alves, F., 2010. Standardization of an indirect Elisa for the diagnosis of feline Immunodeficiency virus. Dissertation. Universidade Federal de Uberlândia, MG.

Almeida, F.M., M.C.F. Faria and A.S. Branco, 2004. Sanitary conditions of a colony of urban feral cats (Feliscatus, Linnaeus, 1758) in a zoological garden of Rio de Janeiro, Brazil. Ver. Inst. Med. S. Trop., 46: 269-274.

Caxito, F.A., F.M. Coelho, M.E. Oliveiraand and M. Resende, 2006. Feline immunodeficiency virus subtype B in domestic cats in Minas Gerais, Brazil. Vet. Res. Commun., 30: 953-956. DOI: $10.1007 / \mathrm{S} 11259-006-3363-8$

Caldas, A.P.F., E.S. Leal, E.F.A. Silva and A.P. Ravazzolo, 2000. Detection of feline immunodeficiency provirus in domestic cats by polymerase chain reaction. Pesquisa Veterinária Brasileira, 20: 20-25.

DOI: $10.1590 / \mathrm{S} 0100-736 \mathrm{X} 2000000100002$ 
Caney, S., 2000. Feline immunodeficiency virus: An update. FIV.

English, R.V., C.M. Johnson, D.H. Gebhard and M.B. Tompkins, 1993. In vivo lymphocyte tropism of feline immunodeficiency virus. J. Virol., 67: 5175-5186. PMID: 7688819

Hartmann, K., 2011. Clinical aspects of feline immunodeficiency and feline leukemia virus infection. Vet. Immunol. Immunopathol., 143: 190-201.

DOI: 10.1016/j.vetimm.2011.06.003

Hayward, J.J., J. Taylor and A.G. Rodrigo, 2007. Phylogenetic analysis of feline immunodeficiency virus in feral and companion domestic cats of New Zealand. J. Virol., 81: 2999-3004.

DOI: 10.1128/JVI.02090-06

Hohdatsu, T., M. Yamada, M. Okada, M. Fukasawa and K. Watanabe et al., 1992. Detection of feline immunodeficiency proviral DNA in peripheral blood lymphocytes by the polymerase chain reaction. Vet. Microbiol., 30: 113-23.

DOI: 10.1016/0378-1135(92)90107-5

Hosie, M.J. and O. Jarrett, 1990. Serological responses of cats to feline immunodeficiency virus. AIDS, 4: 215-220. PMID: 2161670.

Lara, V.M., S.A. Taniwaki and J.P.A. Junior, 2008. Occurrence of feline immunodeficiency virus infection in cats. Ciência Rural, 38: 2245-2249. DOI: $10.1590 / \mathrm{S} 0103-84782008000800024$

Lairmore, M.D., 2011. Retroviridae. In: Fenner'sVeterinary Virology, MacLachlan, N.J. and E.J. Dubovi (Eds.), San Diego, CA, USA: Academic Press of Elsevier, pp: 242-274.

Levy, J., C. Crawford, K. Hartmann, R.H. Lehmann and S. Little et al., 2008. American association of feline practitioners' feline retrovirus management guidelines. J. Feline Med. Surg., 10: 300-316. DOI: $10.1016 /$ j.jfms.2008.03.002

Marçola, T.G., C.P.C. Gomes, P.A. Silva, G.R. Fernandes and G.R. Paludo et al., 2013. Identification of a novel subtype of feline immunodeficiency virus in a population of naturally infected felines in the Brazilian Federal District. Virus Genes, 46: 546-550. DOI: $10.1007 / \mathrm{s} 11262-013-0877-3$

Norris, J.M., E.T. Bell, L. Hales, J.A.L.M.L. Toribio and J.D. White et al., 2007. Prevalence of feline immunodeficiency virus infection in domesticated and feral cats in eastern Australia. J. Feline Med. Surg., 9: 300-308. DOI: 10.1016/j.jfms.2007.01.007

Paillot, R., S. Richard, F. Bloas, F. Piras and H. Poulet et al., 2005. Toward a detailed characterization of feline immunodeficiency virus-specific $\mathrm{T}$ cell immune responses and mediated immune disorders. Vet. Immunol. Immunopathol., 106: 1-14.

DOI: $10.1016 /$ j.vetimm.2004.12.023
Reche, Jr. A., M.K. Hagiwara and S.R.R. Lucas, 1997. Clinical study of acquired immunodeficiency syndrome in domestic cats in Sao Paulo. Braz. J. Vet. Res. Anim. Sci., 34: 152-155.

Richards, J.R., T.H. Elston, R.B. Ford, R.M. Gaskell and K. Hartmann et al., 2006. The 2006 American Association of Feline Practitioners: Feline Vaccine Advisory Panel Report. J. Am. Vet. Med. Association, 229: 1405-1441.

DOI: $10.2460 /$ javma.229.9.1405

Sellon, R.K. and K. Hartmann, 2006. Feline Immunodeficiency Virus Infection. In: Infectious Diseases of the Dog and Cat, Greene, C.E. (Ed.) St. Louis, Missouri, USA: Saunders Elsevier, pp: 131-142.

Souza, H.J.M. and C.H.R. Teixeira, 2002. Estudo epidemiológico de infecções pelo vírus da leucemia e/ou imunodeficiência felina, em gatos domésticos do município do Rio de Janeiro. Clin. Vet., 36: 14-21.

Sparkes, A.H., C.D. Hopper, W.G. Millard, T.J. Gruffydd-Jones and D.A. Harbour, 1993. Feline immunodeficiency virus infection clinicopathologic findings in 90 naturally occurring cases. J. Vet. Intern. Med., 7: 85-90.

DOI: 10.1111/j.1939-1676.1993.tb03174.x

Stutzer, B., F. Muller, M. Majzoub, H. Lutz and C.E. Greene et al., 2010. Role of latent feline leukemia virus infection in nonregenerative cytopenias of cats. J. Vet. Intern. Med., 24: 192-197. DOI: 10.1111/j.1939-1676.2009.0417.x

Tandon, R., V. Cattori, A.C. Pepin, B. Riond and M.L. Meli et al., 2008. Association between endogenous feline leukemia virus loads and exogenous feline leukemia virus infection in domestic cats. Virus Res., 135: 136-143.

DOI: 10.1016/j.virusres.2008.02.016

Teixeira, B.M., D.S. Rajão, J.P.A. Haddad, R.C. Leite and J.K.P. Reis et al., 2007. Occurrence of feline immunodeficiency virus and feline leukemia virus in Sheltered domestic cats of Belo Horizonte. Arquivo Brasileiro Medicina Veterinária Zootecnia, 59: 939-942.

DOI: 10.1590/S0102-09352007000400019

Torres, A.N., K.P. O’Halloran, L.J. Larson, R.D. Schultz and E.A. Hoover, 2010. Feline leukemia virus immunity induced by whole inactivated virus vaccination. Vet. Immunol. Immunopathol., 134: 122-131. DOI: 10.1016/j.vetimm.2009.10.017

Yamamoto, J.K., E. Sparger, E.W. Ho, P.R. Andersen and T.P. O'Connor et al., 1998. Pathogenesis of experimentally induced feline immunodeficiency virus infection in cats. Am. J. Vet. Res., 49: 1246-58. PMID: 2459996 